\title{
Comparison of relative and k0 neutron activation analysis methods at MA-R1 TRIGA MARK II Research Reactor of CNESTEN (Morocco)
}

\author{
Hassan Chahidi ${ }^{1 *}$, Hamid Bounouira ${ }^{2}$, Hamid Amsil ${ }^{2}$, Abdelmajid Choukri ${ }^{1}$, Khalid Embarch $^{2}$, Abdessamad \\ Didi $^{2}$, Ilias Aarab ${ }^{2}$; Khalid Laraki ${ }^{2}$, and Hamid Marah $^{2}$ \\ ${ }^{1}$ Unité de Recherche en Physique et Techniques Nucléaires, Département de Physique, Faculté des Sciences, Université \\ IbnTofail, Kenitra, B.P 242 Kénitra, Maroc. \\ ${ }^{2}$ Centre National de l'Energie, des Sciences et Techniques Nucléaires (CNESTEN), B.P. 1382 R.P. 10001 - Rabat - Maroc \\ Maroc.
}

\begin{abstract}
Since the installation of the TRIGA MARK II reactors in the National Centre for Nuclear Energy, Science and Technology (CNESTEN), Neutron Activation Data Analysis software (NADA) for neutron activation analysis (NAA) based on the relative method was the first software used; Over the years, the neutron activation analysis laboratory has been seeking to develop other softwares based on k0-INAA standardization namely the K0-IAEA software and the k0 software for Windows. In this paper we will focus on the comparison between the performance of $\mathrm{k} 0$ software for Windows and NADA. We compared the results obtained by the NADA Software and k0 for windows for the same input parameters (sample mass, nuclear data, net peak area for the same gamma line and cooling measurement times). In the neutron activation analysis laboratory of the National Center for Nuclear Energy, Science and Technology (CNESTEN) we analysed several reference materials (RM) or certified reference materials (CRM) and WEPAL samples. In this analysis, only certified or recommended values were used to compare the two processes for the different elements.
\end{abstract}

\section{Introduction}

The NAA method (Neutron Activation Analysis) is a multi-element analysis method, the relationship between the concentration of the element and the measured signal is independent of the matrix. [1] The qualities of the NAA method are enhanced by its excellent sensitivity (below ppm, ppb or even ppt level). This makes this method classified as an extremely powerful analytical tool for which all sources of systematic or random variation are identifiable and predictable at the limits of detection. In recent years a variant of the neutron activation analysis method; absolute and k0-NAA (simple comparator) have been proposed and applied in many areas. The ideas led to a procedure bringing together the characteristics of experimental simplicity, high precision, excellent flexibility (irradiation and measurement conditions) and appropriate automation. These aspects were really the main topics raised since 1974, whose concern is the standardization $\mathrm{k} 0$.

Nevertheless, the drawbacks of the relative method have prompted more research on how to calculate the masses of the elements directly from the gamma ray spectrum, what information about the neutron flux in the irradiation position and what nuclear data concerning the target and the nuclides produced would be necessary to be able to make this calculation. The application of the absolute neutron activation method dates back more than 50 years. [2] GIRADI and al. wrote the first systematic methodological survey in the days of the scintillation detectors. [3] After that; more recent applications and developments have been written by several authors. $[4,5]$ It has been pointed out, in the articles mentioned above, that uncertainties in nuclear data were the main source of systematic error in attempts to perform an activation analysis in an absolute manner. These errors amounted to about 20\%. [6] With Improvements in nuclear data and measurements of neutron flux parameters it allows us uncertainties to be reduced to less than 10\%.[7] The efficiency of the detectors can also be estimated with a reasonable precision of about $3 \%$. Today, nearly all of activation analyzes performed use the relative technique. In this method, a pure sample of known mass (standard) containing the desired element and the unknown sample are irradiated simultaneously in the same stream. Under identical conditions, the specific activity (decay rate per mass 
of element) of the standard and of the sample is the same.

A different method has also been developed; taking an intermediate position between the relative and absolute method, trying to combine the advantageous methodological features of the absolute method with the accuracy and precision of the relative. The comparator Method has been studied in detail by GIRARDI and al. [8] and later by DECORTE and al. [9] and SIMONTIS and al. [10] The comparator method is based on the determination of $\mathrm{K} 0$.

Currently, k0-NAA is implemented and used in several laboratories around the world. Morocco is one of the countries applying this technique. After its development, the idea of developing the method matured and it has been the subject of this current work. [11-13]

The $\mathrm{k} 0$ standardization method in neutron activation analysis (k0-NAA) requires a very careful calibration of the input quantities including thermal, epi-thermal and fast neutron fluxes and detector calibration data (reference efficiency and peak-tototal), as well as the solid photo angle at full energy and coincidence counting effects.

In this work, we focused on comparing between the results obtained by the NADA software based on the relative INAA method and $\mathrm{k} 0$-windows that was recently validated in the laboratory [11] using various soil, sediment and plant reference materials from different producers (IAEA, NIST and Wepal)[14-16]. The experimental part was carried out following the standard procedures of the related techniques of the INAA and $\mathrm{k} 0$ method for preparation, irradiation and measurement on an HPGe detector. Two plant samples and four soil samples were analysed by both NADA and K0 Windows software using the same spectra, in 2 irradiation positions of the reactor, mainly, rotary specimen rack (RSR) for long periods and pneumatic transfer system (PTS) for short periods [12] in order to compare the different results.

\section{Experimental part}

\subsection{Sample preparation}

Soil, sediment and plant samples were received from IAEA (Austria), NIST (USA) and Wepal (Netherland) stored in the laboratory at room temperature (Table 1).

Four samples of the wepal (one of the plant matrix (ech. 215) and three of the soil matrix (ech. 890, 919, 961) see Table 1) and one NIST MRC (Peach Leaves SRM-1547) and one IAEA MR (SL-3 soil 7) were prepared in pure polyethylene capsules (diameter 10 and height less than $22 \mathrm{~mm}$ ) taking into account their irradiation.
Four replicates were prepared for each sample. For plant samples, the mass varies from 206 to $340 \mathrm{mg}$ for short-term irradiation and from 180 to $200 \mathrm{mg}$ for long-term irradiation. For soils, the mass varies from 240 to $290 \mathrm{mg}$ for short-term irradiation and from 97 to $120 \mathrm{mg}$ for long-term irradiation.

A199/Co1 (Atomic\%) wire (disc $6 \mathrm{~mm}$ in diameter and $0.1 \mathrm{~mm}$ thick) was used as flux monitor for irradiation for long periods and the sublimed sulphur powder of a mass varies from 610 to $690 \mathrm{mg}$ has been used for short periods. The Zinc monitor (disc $6 \mathrm{~mm}$ in diameter and $0.1 \mathrm{~mm}$ thick) was also used for the analysis of the peach-leaves sample for short and long periods.

For the different reference multi-standards that were used as comparators to determine the concentrations of elements by the relative INAA method, solutions of the 26 mono standards were used in the preparation of the stock solutions.

According to the mono element certificates, the concentration of each element in the solution is 1000 ppm $(\mu \mathrm{g} / \mathrm{kg})$.

To make the different mother solutions a volume of $1 \mathrm{ml}$ of each element was pipetted and then mixed in plastic centenarians. Then $50 \mu \mathrm{l}$ was pipetted from each stock solution by an electronic micropipette and deposited on a filter to avoid radiolysis phenomena and the risk of contamination during irradiation in the reactor. Then once the masses are measured (by Mettler electronic scale) and noted, each standard is enclosed and then sealed

Table 1. List of WEPAL samples analyzed

\begin{tabular}{|c|c|c|c|}
\hline Sample & $\begin{array}{r}\text { Sample } \\
\text { ID }\end{array}$ & Type & Country \\
\hline 2 & 215 & $\begin{array}{l}\text { Paprika/ } \\
\text { pepper (fruit + } \\
\text { leaf)/ } \\
\text { Capsicum sp }\end{array}$ & $\begin{array}{l}\text { Wageningen/ } \\
\text { Netherlands }\end{array}$ \\
\hline 3 & 890 & Sandy soil & $\begin{array}{l}\text { Hengelo/ } \\
\text { Netherlands }\end{array}$ \\
\hline 4 & 919 & Sandy soil & $\begin{array}{l}\text { Halle/ } \\
\text { Netherlands }\end{array}$ \\
\hline 5 & 961 & Clay & $\begin{array}{l}\text { Herveld/ } \\
\text { Netherlands }\end{array}$ \\
\hline
\end{tabular}

\subsection{Irradiation}

Samples, monitors and comparators were irradiated in two irradiation positions in CNESTEN's TRIGA Mark II reactor. The PTS facility $\left(\phi_{t h}=8.48 *\right.$ $10^{11} \pm 8.48 * 10^{9}$ et $\phi_{r}=3.57 * 10^{15} \pm 3.57 *$ $10^{13}$ ) for short-period irradiation and the RSR rotary specimen rack facility $\left(\phi_{t h}=3.1 * 10^{15} \pm 3.1 *\right.$ $10^{13}$ et $\phi_{r}=3.77 * 10^{14} \pm 3.77 * 10^{12}$ ) for longterm irradiation.

In the case of short irradiations, the sample and comparator were placed in plastic capsules and placed in a polyethylene shuttle with zinc wire as a flux monitor for peach leaves, and sulfur as a flux monitor for wepal samples and soil-7. The shuttles 
thus prepared were irradiated for $30 \mathrm{~s}$ to $2 \mathrm{~min}$. For long irradiations, samples and comparators were weighed and prepared as a sandwich with the flux monitors (Zinc sheet for peach leaves and $\mathrm{Al} / \mathrm{Co}$ (Atomic \%) wire for soil-7 and wepal) and then wrapped in plastic bags. Samples and flux monitors prepared were placed in a polyethylene rabbits and irradiated for about 4 hours.

The relevant fluence parameters, $\alpha$ and $\mathrm{f}$, describing the shape of the neutron spectra for the two irradiation facilities used, were experimentally determined at $-0.00034 \pm 0.00001$ and $18.69 \pm 0.51$, respectively for the PT channel and at $0.05351 \pm$ 0.0005 and $36.16 \pm 1.36$ for the RSR channel.[12]

\subsection{Treatment of the sample after irradiation}

Samples, comparators and flus monitors were separated from each other, and then placed in polyethylene capsules suitable for counting.

All operations are done behind a lead wall to protect the manipulator from irradiation. The samples are then taken to the low-background counting room where they will be stored in a lead castle before being analysed on gamma-ray detectors.

The measurements were carried out on two perfectly calibrated HPGe detectors with a relative efficiency of 30 and $70 \%$. Measurements were carried out at such distances with a dead time lower than $10 \%$ with negligible random coincidences. The detector with a relative efficiency of $70 \%$ was connected to a multichannel analyser (MCA) with Genie 2000 spectroscopy software, while the detector with $30 \%$ efficiency was connected to an ORTEC Spectrum Master with Maestro-32 spectroscopy software.

The HyperLab program was used to evaluate the area of the peaks and the adjustment of the spectra used by the $\mathrm{k} 0$ windows software, unlike the NADA software the spectra were processed directly by the software.

For most of the samples analysed we note that the uncertainties are less than $10 \%$ in the most cases and a maximum of $50 \%$ for the other cases which is consistent with Decorte's statement. For the difference between the uncertainties between the two software is probably due to the different calculation approach for each software.
Total efficiency and peak ratio were measured using recommended sources $\left({ }^{137} \mathrm{Cs}\right.$ and ${ }^{152} \mathrm{Eu}$ with certified activities) using k0 IAEA software. Then they were introduced into both programs, the data used were the same and the adjustment of the curves was done using the procedures contained in the individual programs. Coincidence factors and solid angles were calculated using kayzero-solcoi software.

\section{Outcome and discussion}

The results obtained for each software were evaluated using the statistical performance parameters $E_{n}$ (1) and Z-score (2).

$E_{n}$ test:

$$
E_{n}=\left|\frac{X_{L a b}-X_{R e f}}{\sqrt{U_{L a b}^{2}+U_{R e f}^{2}}}\right|
$$

$U_{L a b}$ is the uncertainty of concentrations found by K0 Windows. For the results to be satisfactory it is necessary that $E_{n}$ is less than 1 .

$U_{L a b}$ was measured by being the deviation of the different results found in the four copies for each sample.

Z-score test:

$$
\text { Z-score }=\frac{X_{L a b}-X_{R e f}}{U_{R e f}}
$$

$U_{R e f}$ is the uncertainty has a $95 \%$ confidence interval (I.C.) of the assigned value, $X_{L a b}$ and $X_{R e f}$ are the concentrations found by $\mathrm{k} 0$ Windows and certified respectively. Laboratory performance is considered satisfactory if $\mid Z$-score $\mid \leq 2$, questionable for $2<\mid Z$ score $\mid \leq 3$, unsatisfactory for $\mid$ Z-score $\mid \geq 3$.

In the sample of plant 215 (Table 2), six elements were determined, Z-score is between -2 and 2 in the two software in most cases except for the $\mathrm{Zn}$ in the Nada software. $E_{n}$ less than or equal to 1 for all elements processed by $\mathrm{k} 0$ for windows, on the other hand for the Nada software the elements $\mathrm{Zn}$ and $\mathrm{Mn}$ have More than 1 
Table 2. Results obtained for the P215 certified reference material from WEPAL

\begin{tabular}{|c|c|c|c|c|c|c|c|c|c|c|c|c|c|}
\hline \multirow{2}{*}{ Element } & \multicolumn{3}{|c|}{ Certified values } & \multicolumn{5}{|c|}{ K0 for Windows values } & \multicolumn{5}{|c|}{ NADA values } \\
\hline & Xref & \pm & Uref & Xlab & \pm & Ulab & Zscore & En & Xlab & \pm & Ulab & Zscore & En \\
\hline $\mathrm{Ca}$ & 14360 & \pm & 1180 & 14483,2 & \pm & 608,547174 & 0,1044 & 0,0928 & 15.793 & \pm & 1.544 & 1,21441 & 0,7374 \\
\hline $\mathrm{Cl}$ & 656,3 & \pm & 93,1 & 631,8932 & \pm & 11,9171884 & $-0,2622$ & 0,26 & 683,6 & \pm & 21,8 & 0,29291 & 0,2852 \\
\hline K & 49330 & \pm & 3990 & 49331,36 & \pm & 1872,71928 & 0,0003 & 0,0003 & 45.755 & \pm & 1.034 & $-0,896$ & 0,8673 \\
\hline $\mathrm{Mn}$ & 141,3 & \pm & 11,8 & 148,9554 & \pm & 3,25305633 & 0,6488 & 0,6254 & 118 & \pm & 1,88 & $-1,9729$ & 1,9483 \\
\hline $\mathrm{Na}$ & 27,76 & \pm & 13,36 & 26,54446 & \pm & 1,16886111 & $-0,091$ & 0,0906 & 20,91 & \pm & 3,48 & $-0,5127$ & 0,4962 \\
\hline $\mathrm{Zn}$ & 53,71 & \pm & 5,07 & 57,6224 & \pm & 7,60198897 & 0,7717 & 0,4282 & 68,69 & \pm & 4,65 & 2,95464 & 2,1775 \\
\hline
\end{tabular}

For sample 919 (Table 3), 11 elements were determined, Z-score is between -2 and 2 and En less than or equal to 1 in most cases except for $\mathrm{Al}$ in both software. We notice that the concentration of the $\mathrm{Al}$ and overestimated in $\mathrm{k} 0$ for windows and underestimated in the NADA software.

Table 3. Results obtained for the S919 certified reference material from WEPAL

\begin{tabular}{llllllllllllllll}
\hline \multirow{2}{*}{ Elements } & \multicolumn{1}{l}{ Certified values } & \multicolumn{1}{c}{ K0 for Windows } & \multicolumn{1}{c}{ Nada } \\
& Xcert & \pm & Ucert & Xlab & \pm & Ulab & Zscore & En & Xlab & \pm & Ulab & Zscore & En \\
\hline $\mathrm{Al}$ & 17910 & \pm & 2100 & 22223,2 & \pm & 1562,5 & 2,0539 & 1,6478 & 13004 & \pm & 226 & $-2,3362$ & 2,3228 \\
$\mathrm{As}$ & 5,567 & \pm & 0,779 & 5,93507 & \pm & 0,20008 & 0,4725 & 0,4576 & 4,92 & \pm & 0,01 & $-0,8306$ & 0,8305 \\
$\mathrm{Ca}$ & 2038 & \pm & 210 & 2210,75 & \pm & 1083,58 & 0,8226 & 0,1565 & 2101 & \pm & 134 & 0,3 & 0,2529 \\
$\mathrm{Ce}$ & 16,07 & \pm & 2,43 & 18,6462 & \pm & 0,94307 & 1,0602 & 0,9883 & 15,75 & \pm & 0,52 & $-0,1317$ & 0,1288 \\
$\mathrm{Cr}$ & 45,69 & \pm & 7,49 & 52,4629 & \pm & 0,38007 & 0,9043 & 0,9031 & 50,6 & \pm & 4,14 & 0,6555 & 0,5737 \\
$\mathrm{~K}$ & 8848 & \pm & 573 & 8642,23 & \pm & 261,26 & $-0,359$ & 0,3267 & 9353 & \pm & 1.090 & 0,8813 & 0,4101 \\
$\mathrm{La}$ & 8,381 & \pm & 1,186 & 8,66545 & \pm & 0,14081 & 0,2398 & 0,2382 & 8,61 & \pm & 0,01 & 0,1931 & 0,1931 \\
$\mathrm{Mn}$ & 231,1 & \pm & 18,3 & $2,35 \mathrm{E}+02$ & \pm & 23,4803 & 0,2023 & 0,1244 & 220,97 & \pm & 2,7 & $-0,5536$ & 0,5476 \\
$\mathrm{Na}$ & 3710 & \pm & 319 & 3871,54 & \pm & 18,1161 & 0,5064 & 0,5056 & 3288 & \pm & 62 & $-1,3229$ & 1,2986 \\
$\mathrm{Sc}$ & 1,493 & \pm & 0,116 & 1,52886 & \pm & 0,18053 & 0,3091 & 0,1671 & 1,47 & \pm & 0,07 & $-0,1983$ & 0,1698 \\
$\mathrm{~V}$ & 26,83 & \pm & 3,37 & 29,4859 & \pm & 0,43374 & 0,7881 & 0,7817 & 21,06 & \pm & 0,31 & $-1,7122$ & 1,705 \\
\hline
\end{tabular}

All the results found by $\mathrm{k} 0$ for Windows in the soil 7 (Table 4) sample have a Z-score between -2 and 2 and En less than or equal to 1 except for the $\mathrm{Mg}$ element which has a Z-score well above 2 which may be due to the low value of the certified uncertainty which somewhat influenced the value. As for the values found by the NADA software, the Zn element has a value that far exceeds 2 for the $\mathrm{z}$-score and 1 for En which is due to the overestimation of the concentration find $(131.80 \mathrm{ppm})$ compared to the certified value (104 ppm). 
Table 4. Results obtained for the certified reference materials: IAEA-Soil-7

\begin{tabular}{|c|c|c|c|c|c|c|c|c|c|c|c|c|c|}
\hline \multirow{2}{*}{ Element } & \multicolumn{3}{|c|}{ Certified values } & \multicolumn{5}{|c|}{ NADA values } & \multicolumn{5}{|c|}{ K0 for Windows values } \\
\hline & Xref & \pm & Uref & Xlab & \pm & Ulab & Zscore & En & Xlab & \pm & Ulab & Zscore & En \\
\hline $\mathrm{Al}$ & 47000 & \pm & 3000 & 50769 & \pm & 1496,238 & 1,256333 & 1,124262 & 46180 & \pm & 1675 & $-0,27333$ & 0,238654 \\
\hline As & 13,4 & \pm & 0,9 & 13,29 & \pm & 2,206173 & $-0,12222$ & 0,046166 & $1,46 \mathrm{E}+01$ & \pm & 1,058494 & 1,382 & 0,895212 \\
\hline $\mathrm{Ba}$ & 159 & \pm & 28 & 206,85 & \pm & 29,48635 & 1,708929 & 1,176758 & 105 & \pm & 16 & $-1,92857$ & 1,674469 \\
\hline $\mathrm{Br}$ & 7 & \pm & 4 & 9,329 & \pm & 0,8 & 0,58225 & 0,570943 & 7,993958 & \pm & 0,631125 & 0,248489 & 0,245453 \\
\hline $\mathrm{Ca}$ & 163000 & \pm & 6000 & 151104 & \pm & 2729,432 & $-1,98267$ & 1,804709 & $1,64 \mathrm{E}+05$ & \pm & 5647 & 0,085333 & 0,06214 \\
\hline $\mathrm{Ce}$ & 61 & \pm & 11 & 56,685 & \pm & 2,340523 & $-0,39227$ & 0,383684 & 61,70607 & \pm & 4,327597 & 0,064188 & 0,059732 \\
\hline Co & 8,9 & \pm & 0,5 & 8,744 & \pm & 0,220617 & $-0,312$ & 0,285448 & 9,11897 & \pm & 0,638985 & 0,43794 & 0,269881 \\
\hline $\mathrm{Cr}$ & 60 & \pm & 11 & 74,38 & \pm & 3,620387 & 1,307273 & 1,241746 & 77,63895 & \pm & 11,33605 & 1,603541 & 1,116689 \\
\hline $\mathrm{Cs}$ & 5,4 & \pm & 0,5 & 5,517 & \pm & 0,4 & 0,234 & 0,182723 & 5,28404 & \pm & 0,53631 & $-0,23192$ & 0,158149 \\
\hline $\mathrm{Eu}$ & 1 & \pm & 0,1 & 1,0035 & \pm & 0,065761 & 0,035 & 0,029243 & 1,026807 & \pm & 0,088093 & 0,26807 & 0,201151 \\
\hline $\mathrm{Fe}$ & 25700 & \pm & 500 & 25292,5 & \pm & 622,9611 & $-0,815$ & 0,510141 & 25719,33 & \pm & 1946,55 & 0,03865 & 0,009616 \\
\hline $\mathrm{Hf}$ & 5,1 & \pm & 0,3 & 5,432 & \pm & 0,121622 & 1,106667 & 1,025591 & $4,97 \mathrm{E}+00$ & \pm & 0,387821 & $-0,43123$ & 0,263853 \\
\hline K & 12100 & \pm & 800 & 12626 & \pm & 704,2784 & 0,6575 & 0,493509 & $1,22 \mathrm{E}+04$ & \pm & 1740,11 & 0,0945 & 0,039474 \\
\hline $\mathrm{La}$ & 28 & \pm & 1 & 26,665 & \pm & 0,417193 & $-1,335$ & 1,232077 & 28,22405 & \pm & 2,048905 & 0,22405 & 0,098271 \\
\hline $\mathrm{Mg}$ & 11300 & \pm & 300 & 11479 & \pm & 400 & 0,596667 & 0,358 & 14221,35 & \pm & 5247,762 & 9,737833 & 0,555777 \\
\hline $\mathrm{Mn}$ & 631 & \pm & 27 & 627 & \pm & 14,14214 & $-0,14815$ & 0,131236 & 632,8097 & \pm & 22,56759 & 0,067025 & 0,051426 \\
\hline $\mathrm{Na}$ & 2400 & \pm & 100 & 2346,5 & \pm & 136,4716 & $-0,535$ & 0,316217 & 2386,153 & \pm & 176,4782 & $-0,13847$ & 0,068268 \\
\hline $\mathrm{Nd}$ & 30 & \pm & 8 & 42,72 & \pm & 2,262742 & 1,59 & 1,529978 & 24,6 & \pm & 3,4 & $-0,675$ & 0,621223 \\
\hline $\mathrm{Rb}$ & 51 & \pm & 4 & 52,33 & \pm & 0,933381 & 0,3325 & 0,323801 & 64,4114 & \pm & 4,508798 & 3,35285 & 2,225081 \\
\hline $\mathrm{Sb}$ & 1,7 & \pm & 0,3 & 2,177 & \pm & 0,032527 & 1,59 & 1,580736 & 2,036365 & \pm & 0,231202 & 1,121217 & 0,888084 \\
\hline $\mathrm{Sc}$ & 8,3 & \pm & 1,4 & 8,3025 & \pm & 0,116673 & 0,001786 & 0,00178 & 8,785458 & \pm & 0,616494 & 0,346755 & 0,317349 \\
\hline $\mathrm{Sm}$ & 5,1 & \pm & 0,3 & 5,03 & \pm & 0,315219 & $-0,23333$ & 0,160861 & 5,124325 & \pm & 0,420086 & 0,081083 & 0,047122 \\
\hline $\mathrm{Ti}$ & 3000 & \pm & 400 & 3076,697 & \pm & 136,7495 & 0,191741 & 0,181432 & 3419,9 & \pm & 239,393 & 1,04975 & 0,900756 \\
\hline V & 66 & \pm & 7 & 61,735 & \pm & 3,867874 & $-0,60929$ & 0,53329 & 61,7238 & \pm & 6,560666 & $-0,61089$ & 0,445722 \\
\hline $\mathrm{Yb}$ & 2,4 & \pm & 0,5 & 2,431 & \pm & 0,3 & 0,062 & 0,053165 & 2,260977 & \pm & 0,209372 & $-0,27805$ & 0,256469 \\
\hline $\mathrm{Zn}$ & 104 & \pm & 3 & 131,85 & \pm & 6,151829 & 9,283333 & 4,069055 & 101,9918 & \pm & 11,47818 & $-0,6694$ & 0,169272 \\
\hline
\end{tabular}

For sample 890 (Table 5), Al has a Z-score value greater than 2 and $E_{n}$ greater than or equal to 1 for NADA software, and $E_{n}$ slightly greater than or equal to 1 for $\mathrm{K} 0$ for windows.

For the soil sample 961 (Table 6), Z-score is between -2 and 2 in the 2 software in most cases except for the $\mathrm{Al}$ in $\mathrm{k} 0$ for windows which has a concentration of $45716 \mathrm{ppm}$ which is a little overestimated compared to the value certified $41290 \mathrm{ppm}$. The concentration of $\mathrm{V}$ found by NADA (23.11 ppm) is largely underestimated compared to the certified value $(51.55 \mathrm{ppm})$ which therefore influenced the results found for Z-score and $E_{n}$. 
Table 5. Results obtained for the $S 890$ certified reference material from WEPAL

\begin{tabular}{|c|c|c|c|c|c|c|c|c|c|c|c|c|}
\hline \multirow{2}{*}{ Element } & \multicolumn{3}{|c|}{ Certified values } & \multicolumn{5}{|l|}{ Nada } & \multicolumn{4}{|c|}{ K0 for Windows } \\
\hline & Xcert & \pm & Ucert & Xlab & \pm & Ulab & Zscore & En & Xlab & \pm Ulab & Zscore & En \\
\hline $\mathrm{Al}$ & 11930 & \pm & 1140 & 17437,5 & \pm & 1702,07 & 4,83114035 & 2,68846128 & 9836 & \pm 170 & $-1,836842$ & 1,81675 \\
\hline As & 1,718 & \pm & 0,227 & 2,0455 & \pm & 0,1659 & 1,44273128 & 1,16480634 & 1,96 & $\pm 0,01$ & 1,0660793 & 1,06505 \\
\hline $\mathrm{Ca}$ & 1238 & \pm & 253 & 1427,25 & \pm & 216,12 & 0,74802372 & 0,56876023 & 1314 & \pm 158 & 0,3003953 & 0,25479 \\
\hline $\mathrm{Ce}$ & 8,643 & \pm & 2,044 & 11,4367 & \pm & 1,10206 & 1,36678082 & 1,20305633 & 7,22 & $\pm 2,04$ & $-0,696184$ & 0,49276 \\
\hline $\mathrm{Cr}$ & 36,06 & \pm & 6,56 & 47,0427 & \pm & 3,68601 & 1,67419207 & 1,45956412 & 35,36 & $\pm 3,64$ & $-0,106707$ & 0,09331 \\
\hline $\mathrm{Fe}$ & 2541 & \pm & 304 & 2545,47 & \pm & 237,143 & 0,01470395 & 0,01159367 & 2062 & \pm 233 & $-1,575658$ & 1,25058 \\
\hline K & 6382 & \pm & 331 & 6443,95 & \pm & 522,909 & 0,18716012 & 0,10010252 & 6258 & \pm 813 & $-0,374622$ & 0,14126 \\
\hline $\mathrm{La}$ & 4,468 & \pm & 0,773 & 4,42937 & \pm & 0,41822 & $-0,0499741$ & 0,0439534 & 5,32 & $\pm 0,01$ & 1,1021992 & 1,10211 \\
\hline $\mathrm{Mn}$ & 75,93 & \pm & 7,59 & 87,158 & \pm & 5,90727 & 1,47931489 & 1,16740667 & 73,01 & $\pm 0,61$ & $-0,384717$ & 0,38348 \\
\hline $\mathrm{Na}$ & 2262 & \pm & 306 & 2696,43 & \pm & 197,617 & 1,41970588 & 1,19262307 & 2254,33 & $\pm 44,04$ & $-0,025065$ & 0,02481 \\
\hline $\mathrm{Sc}$ & 0,866 & \pm & 0,1693 & 0,941853 & \pm & 0,10903 & 0,44803898 & 0,37668225 & 0,79 & $\pm 0,06$ & $-0,448907$ & 0,42312 \\
\hline
\end{tabular}

Table 6. Results obtained for the S961 certified reference material from WEPAL

\begin{tabular}{llllllllllllll}
\hline \multirow{3}{*}{ Element } & \multicolumn{3}{c}{ Certified values } & \multicolumn{9}{c}{ K0 for Windows values } & \multicolumn{7}{c}{ Nada values } \\
& Xcert & \pm & Ucert & Xlab & \pm & Ulab & Zscore & En & Xlab & \pm & Ulab & Zscore & En \\
\hline $\mathrm{Al}$ & 41290 & \pm & 3270,841 & 45716,2 & \pm & 663,75 & 2,258265 & 1,16078 & 37.490 & \pm & 655 & $-1,16178$ & 1,139164 \\
$\mathrm{As}$ & 9,707 & \pm & 0,818273 & 9,93995 & \pm & 0,200042 & 0,225072 & 0,17656 & 8,13 & \pm & 0,01 & $-1,92723$ & 1,927087 \\
$\mathrm{Ba}$ & 386,8 & \pm & 33,94593 & 345,261 & \pm & 6,1005 & $-1,42257$ & 0,92769 & 365,81 & \pm & 41,94 & $-0,61834$ & 0,389018 \\
$\mathrm{Br}$ & 4030 & \pm & 249,6817 & 3686,81 & \pm & 12,31 & $-1,42402$ & 0,98897 & 4.456 & \pm & 501 & 1,706173 & 0,761027 \\
$\mathrm{Ce}$ & 67,24 & \pm & 6,070102 & 73,6779 & \pm & 1,972909 & 0,939839 & 0,7034 & 66,57 & \pm & 3,65 & $-0,11038$ & 0,094593 \\
$\mathrm{Co}$ & 8,763 & \pm & 0,646772 & 8,55615 & \pm & 0,112895 & $-0,25728$ & 0,20046 & 8,05 & \pm & 1,39 & $-1,1024$ & 0,465069 \\
$\mathrm{Cr}$ & 79,91 & \pm & 6,550493 & 92,9961 & \pm & 0,605723 & 1,708368 & 1,29836 & 69,74 & \pm & 6,28 & $-1,55255$ & 1,120717 \\
$\mathrm{Cs}$ & 2,93 & \pm & 0,251714 & 2,92132 & \pm & 0,09155 & $-0,03179$ & 0,02338 & 3,27 & \pm & 0,16 & 1,350741 & 1,13994 \\
$\mathrm{Fe}$ & 19380 & \pm & 1461,12 & 19455 & \pm & 351,9141 & 0,072816 & 0,04195 & 15.769 & \pm & 152 & $-2,47139$ & 2,458127 \\
$\mathrm{~K}$ & 15895 & \pm & 1231,012 & 15183,1 & \pm & 305,4586 & $-0,81082$ & 0,47082 & 17.965 & \pm & 1.118 & 1,681544 & 1,244796 \\
$\mathrm{Mn}$ & 603,1 & \pm & 50,95872 & 615,417 & \pm & 16,25952 & 0,299684 & 0,18814 & 745,54 & \pm & 4,37 & 2,795204 & 2,784982 \\
$\mathrm{Na}$ & 6985 & \pm & 545,0976 & 7013,25 & \pm & 61,43856 & 0,080256 & 0,04354 & 7.878 & \pm & 102 & 1,638239 & 1,610289 \\
$\mathrm{Rb}$ & 73,12 & \pm & 4,691249 & 77,1602 & \pm & 1,188915 & 1,164323 & 0,69239 & 74,23 & \pm & 2,32 & 0,236611 & 0,212092 \\
$\mathrm{Sc}$ & 7,139 & \pm & 0,532513 & 7,17957 & \pm & 0,101456 & 0,070927 & 0,05191 & 6,71 & \pm & 0,11 & $-0,80561$ & 0,788958 \\
$\mathrm{~V}$ & 51,55 & \pm & 4,099627 & 57,6506 & \pm & 0,7808 & 1,854286 & 1,16058 & 23,11 & \pm & 0,68 & $-6,93722$ & 6,843712 \\
\hline & & & & & & & & & & & &
\end{tabular}

Finally, for the peach leaves sample (Table 7), thirteen elements were determined by the two softwares. For the $\mathrm{k} 0$ for windows, only the two elements $\mathrm{Ca}$ and $\mathrm{Sc}$ have a Z-score greater than 2 , and only one element $\mathrm{Sc}$ that has $E_{n}$ greater than 1 . While for NADA four elements (Al, Ca, Fe and Sm) have a Z-score greater than 2 and $E_{n}$ greater than 1 for the elements $\mathrm{Ca}$ and $\mathrm{Sm}$. 
Table 7. Results obtained for the standard reference materials: Peach leaves (SRM 1547)

\begin{tabular}{llllllllllllll}
\hline \multirow{3}{*}{ Element } & \multicolumn{3}{l}{ Certified values } & \multicolumn{3}{c}{ Nada values } & \multicolumn{7}{c}{ K0 for Windows values } \\
& Xref & \pm & Uref & Nada & \pm & inc & Zscore & En & Xlab & \pm & Ulab & Zscore & En \\
\hline $\mathrm{Al}$ & 248,9 & \pm & 6,5 & 234 & \pm & 7,5 & $-2,29231$ & 1,501302 & 243,8 & \pm & 23,85317 & $-0,78462$ & 0,206286 \\
$\mathrm{Br}$ & 11 & \pm & 1,1 & 9,953 & \pm & 0,145 & $-0,95182$ & 0,943655 & 12,63483 & \pm & 1,091552 & 1,486212 & 1,054954 \\
$\mathrm{Ca}$ & 15590 & \pm & 160 & 13594 & \pm & 590 & $-12,475$ & 3,265119 & $1,60 \mathrm{E}+04$ & \pm & 1230,686 & 2,359583 & 0,304206 \\
$\mathrm{Fe}$ & 219,8 & \pm & 6,8 & 239,6 & \pm & 36,8 & 2,911765 & 0,529087 & 227,3583 & \pm & 16,70564 & 1,111507 & 0,419051 \\
$\mathrm{~K}$ & 24330 & \pm & 380 & 24028 & \pm & 705 & $-0,79474$ & 0,37708 & $2,44 \mathrm{E}+04$ & \pm & 2110,156 & 0,187263 & 0,033189 \\
$\mathrm{La}$ & 9 & \pm & 0,9 & 8,448 & \pm & 0,11 & $-0,61333$ & 0,608803 & 9,664786 & \pm & 0,703586 & 0,738651 & 0,58193 \\
$\mathrm{Mg}$ & 4320 & \pm & 150 & 4403 & \pm & 175 & 0,553333 & 0,360105 & 4564,97 & \pm & 460,1769 & 1,633133 & 0,506129 \\
$\mathrm{Mn}$ & 97,8 & \pm & 1,8 & 95,87 & \pm & 1,52 & $-1,07222$ & 0,81921 & $1,00 \mathrm{E}+02$ & \pm & 7,890006 & 1,442478 & 0,320839 \\
$\mathrm{Na}$ & 23,8 & \pm & 1,6 & 25,66 & \pm & 4,31 & 1,1625 & 0,404576 & $2,73 \mathrm{E}+01$ & \pm & 4,027507 & 2,15625 & 0,79609 \\
$\mathrm{Rb}$ & 19,65 & \pm & 0,89 & 18,03 & \pm & 1,61 & $-1,82022$ & 0,880617 & 19,68155 & \pm & 1,573122 & 0,035449 & 0,017456 \\
$\mathrm{Sc}$ & 0,04 & \pm & 0,004 & 0,044848 & \pm & 0,004822 & 1,212 & 0,773808 & 0,049094 & \pm & 0,004749 & 2,273554 & 1,464697 \\
$\mathrm{Sm}$ & 1 & \pm & 0,1 & 1,388 & \pm & 0,015 & 3,88 & 3,837073 & 1,06983 & \pm & 0,081669 & 0,6983 & 0,54085 \\
$\mathrm{~V}$ & 0,367 & \pm & 0,038 & 0,371916 & \pm & 0,08599 & 0,129368 & 0,052291 & 0,336447 & \pm & 0,024941 & $-0,80403$ & 0,672179 \\
\hline
\end{tabular}

So we can conclude that in the majority of elements $E_{n}$ is less than 1 and Z-score between -2 and 2 except in a few elements; and these elements vary from one matrix to another and therefore systematic error can be excluded. For uncertainties found in the laboratory, they are acceptable in most cases.

We can also conclude that the results found by the $\mathrm{k} 0$ for windows software are better than the results found by NADA; which may be due to the performance of both software, or perhaps the use of multi-standard has decreased the concentrations of the different elements in the latter; and that may have influenced the calculation of concentrations for some elements.

the accuracy of the results may also be due to other sources of error, which can lead to biased results. Some of these possible sources of error are listed below:

1- Flux variation and flux monitoring error: This problem can arise when standards and / or samples are stacked and irradiated in the same position. It has been shown that when using two capsules, the change in flux through the samples is estimated to be approximately $1 \%$. [17] The temporal variation in flux occurs when irradiating samples in a non-constant neutron flux. Fortunately, this is less likely to happen in thermal reactors. However, when using the relative method or the comparator, these errors are minimized because the samples and standards or the comparator see the variations.

2- Errors due to flow parameters, nuclear data and growth patterns: The typical uncertainties of thermal and epi-thermal fluxes in bare irradiation channels are $1.5 \%$ and $10 \%$, respectively. For Q0, the uncertainties of the nuclear data range from $1.5 \%$ to $13 \%$.

3- Error due to detector efficiency: The expression of the error due to the efficiency of ray detection at a particular sourcedetector distance mainly includes uncertainties in the activity of the calibration sources and statistical errors. The interpolation error ranges from 2 to $6 \%$ in the energy range $70-121 \mathrm{KeV}$, from 1.2 to $1.6 \%$ in the range $133-1121 \mathrm{KeV}$, and from 1.3 to $4 \%$ in the range $1173-1691$ Kev.[17]

4- Error due to counting statistics: it affects the accuracy of measurements. They vary from 1 to $10 \%$ and in some cases more than $10 \%$. It is considered as the main source of random errors.

5- Error due to neutron self-protection and $\gamma$ self-absorption: Most major elements such as $\mathrm{Si}, \mathrm{Al}, \mathrm{Fe}, \mathrm{Na}, \mathrm{Ca}, \mathrm{K}$, etc. have a low absorption cross section. On the other hand, some nuclides show high resonance absorption in the epithermal region. These elements will in many cases be present in trace amounts in the samples and, therefore, will not pose any problem with regard to 
neutron absorption. In general, selfprotection can be neglected. The gamma absorption in the sample is normally neglected for energies above $100 \mathrm{keV}$. However, at low energy as in 153Sm (69 $\mathrm{keV}$ ), this effect, depending on the type of matrix, can lead to a large error.

6- Other errors: The error due to the evaluation of the peak area is estimated to be $<1 \%$ in most cases. The maximum dead time in samples is $12 \%$. The correction error for losses due to dead time and pulse accumulation is approximately $1 \%$.

Finally, we will discuss the advantages and disadvantages of each method. Starting with the Relative method: This method is simple to use, precise and exact if the standard (s) available are of similar composition to that of the sample. It eliminates many errors such as those due to flow parameters, nuclear data, decay pattern, efficiency, self-protection and coincidence summation, etc. On the other hand, the time required to irradiate and count the standard and the difficulty in maintaining and ensuring the stability of the chemical standard remains important. It is important to make the right choice of standard, a choice impacted by many factors, we mention: purity, solubility in solvents, humidity, weighing, resistance to radiation and decomposition, etc. In addition, differences in matrix composition between sample and standard will contribute additional uncertainty.[8-10]

On the other hand, for the second simple comparator method (k0 -NAA) we benefit from the elimination of the problem of flux variations. In addition, the flux ratio, efficiency, $\mathrm{k} 0$, etc. can be determined with precision, thus reducing the contributions to the total uncertainty. Nevertheless, the problem of choosing the appropriate comparators for the multi-element analysis may not be easy with regard to the nuclear data and the parameters of the decay scheme. In daily NAA practice, counting at small source-to-detector distances for large sources is common, problems with correcting coincidences and attenuation can involve a tedious calibration procedure, experimental corrections, and computation. Complicated computing.[8-10]

\section{Conclusion}

It can be concluded from the results found that most of the results of both software are satisfactory with more precision in most cases for those analyzed by $\mathrm{k} 0$ for windows.
It is also noted that the need to use standards for each element in the relative method used by the NADA software limits the number of elements analysed by the number of these standards, unlike the $\mathrm{k} 0$ software for windows which requires only one flow monitor for each sample.

Regarding the use of softwares: $\mathrm{k} 0$ for windows software is easier, faster and more comfortable compared to Nada software, since $\mathrm{k} 0$ for windows software automatically calculates irradiation and cooling and measurement times and contains a database of all data concerning all the elements analysed; otherwise, in the Nada software, we have to enter all these previously mentioned data manually. In addition, peak detection must be done manually for the NADA software while the $\mathrm{k} 0$ software for windows does it automatically.

\section{References}

1. T. Bereznai, "Methods, problems and trends of standardization in multielement reactor neutron activation analysis." Anal. Bioanal. Chem. 302.5: 353-363 (1980).

2. G. E. BOYD, Method of activation analysis. Anal. Chem., vol. 21, no 3, p. 335347 (1949).

3. F. Girardi, G. Guzzi, \& J. Pauly, Activation Analysis by Absolute Gamma Ray Counting and Direct Calculation of Weights from Nuclear Constants. Anal. Chem., 36(8), 1588-1594 (1964)

4. Ricci, Enzo. "Methodology for high-flux absolute multielement neutron activation analysis-environmental baselines by analysis of tree rings." Anal. Chim. Acta ,79: 109-124 (1975)

5. R.HEFT, R.KOSZYKOWSKI, Analysis of standard reference materials by absolute INAA, J.R.NC, vol. 72, no 1-2, p. 245-261 (1982)

6. Lyon, W. S. "Guide to activation< analysis. DV Nostrand Company." INC, Princeton, New Jersey (1964).

7. S. I. Kafala, T. D. Macmahon. "Neutron activation analysis without multi-element standards." J.R.N.C., 169.1: 187-199 (1993)

8. F. Girardi, G. Guzzi, J. Pauly, Reactor Neutron Activation Analysis by the Single Comparator Method, Anal. Chem., 37(9), 1085-1092 (1965)

9. F. De Corte, A. Speecke, J. Hoste, Reactor neutron activation analysis by a triple comparator method. J.R.C., 3(3), 205-215 (1969) 
10. A. Simonits, F. De Corte, J. Hoste. "Single-comparator methods in reactor neutron activation analysis." J.R.N.C., 24.1: 31-46 (1975)

11. H. Chahidi, et al. "Performance of k0 standardization method in neutron activation analysis using Kayzero for Windows software at the National Center for Energy, Sciences and Nuclear Techniques (CNESTEN-

Morocco)." J.R.N.C., 327.1: 59-64 (2021)

12. H. Bounouira, et al. "Neutron flux characterization of the Moroccan Triga Mark II research reactor and validation of the $\mathrm{k} 0$ standardization method of NAA using k 0-IAEA

program." J.R.N.C., 300.2: 465-471 (2014)
13. H. Amsil, et al. "Neutron beam characterization for the Moroccan TRIGA Mark II reactor." J.R.N.C., 327.3: 10631072 (2021)

14. WEPAL. http://www.wepal.nl/. Accessed 01 Sept (2017)

15. NIST SRM-2711. https://wwws.nist.gov/srmors/certificates/archives/271 1.pdf. Accessed 01 Sept (2017)

16. NIST SRM 1547. https://wwws.nist.gov/srmors/certificates/1547.pdf. Accessed 01 Sept (2017)

17. S.I. Kafala, and T. D. MacMahon. "Comparison of neutron activation analysis methods." J.R.N.C., 271.2: 507516 (2007) 